\title{
Industria cultural y relaciones 'cara a cara' en las redes: la continuidad del cambio en España
}

\author{
Luis NúÑEZ LADEVÉZE \\ ladeveze@ceu.es \\ Universidad San Pablo-CEU \\ José Antonio IRISARRI \\ jairisarri@saviacp.com \\ Centro Universitario Villanueva (UCM)
}

Recibido: 28 de febrero de 2014

Aceptado: 25 de junio de 2014

\section{Resumen}

En la sociedad digital las relaciones personales face to face se establecen a distancia simultáneamente entre innumerables usuarios que interactúan con autonomía. A pesar de esta impresionante novedad, los datos muestran que en España no cambian los hábitos ni las preferencias de los usuarios respecto de las que conformaron las grandes audiencias televisivas en la precedente sociedad de consumo de masas. La audiencia convencional aumenta y la aparición de la televisión social muestra que un medio esencialmente interpersonal puede amalgamarse con medios unidireccionales como la radio y el televisor. Al transformarse la sociedad de masas en una sociedad virtual de relaciones interpersonales a distancia, la inclinación al entretenimiento también se mantiene como uso predominante. En el espacio virtual, saber es saber discernir y cada sujeto del proceso es responsable de lo que encuentra. Los criterios de autoridad se desplazan sin que ese cambio altere los gustos predominantes de la anterior sociedad industrial de consumo en masa.

Palabras clave: Medios de comunicación, industria cultural, audiencias, influencia personal, redes virtuales, entretenimiento, televisión social.

\section{Cultural Industry and Relations face to face on the Networks: Continuities of Change in Spain}

\begin{abstract}
In the digital society, personal relationships face to face are established distance and simultaneously among users that interact with autonomy. Despite this impressive novelty, data show that in Spain neither habits nor users preferences change with respect to those forming the large television audiences in the preceding mass consumer society. Conventional audience have continuously increased and the recent emergence of social TV shows that an essentially interpersonal media may blend with one-way media like radio and TV. As the mass society has been transformed into a virtual society of interpersonal distance relationships, the inclination to entertainment still remains as a predominant use. In the virtual space to know is to discern and each individual in the process is responsible for his findings. Authority criteria move without that change altering the prevailing tastes of the previous industrial society of mass consumption.
\end{abstract}

Keywords: Mass media, cultural industry, audiences, personal influence, social network, social televisión, entertainment.

\section{Referencia normalizada}

NÚÑEZ LADEVÉZE, Luis e IRISARRI, José Antonio (2015): “Industria cultural y relaciones 'cara a cara' en las redes: la continuidad del cambio en España”. Estudios sobre el Mensaje Periodístico. Vol. 21, Núm. 1 (enero-junio), págs.: 471-490. Madrid, Servicio de Publicaciones de la Universidad Complutense. 
Sumario: 1. Planteamiento. 2. De la crítica a la cultura de masas a la cultura digital. 3. El nuevo escenario de la personalización del mercado. 4. Flujos de la demanda en la red. 5. Continuidad y discontinuidad en el cambio. 6. Aspectos de la discontinuidad; 6.1. La nueva cotidianidad de la proximidad 'cara a cara' a distancia; 6.2. Dispersión de los fundamentos; 6.3. Responsabilidad de las autonomías personales; 6.4. Problematicidad de una moral dominante; 6.5. Hacia nuevos procesos regulatorios. 7. Conclusiones. 8. Referencias bibliográficas. 9. Notas.

\section{Planteamiento}

La voz "pantalla", antes asociada habitualmente al televisor, ha ampliado su campo designativo abarcando desde la más pequeña de los móviles, la intermedia de los ordenadores, la mediana de las tabletas, las grandes de los receptores a las más amplias de las salas cinematográficas, o cualquiera de los múltiples artilugios mediante los que se puede atender a un contenido audiovisual. El constante progreso de la tecnología comunicativa deja pronto envejecidas las innovaciones anteriores. Sin embargo, puede que los aspectos de fondo no hayan evolucionado tanto como podría parecernos por el seductor deslumbramiento que produce la renovación tecnológica. En trabajos precedentes hemos consignado que "los cambios no afectan a la sustancia antropológica, sino a la economía social de los procesos comunicativos" (Núñez Ladevéze, Álvarez de Mon y Núñez Canal, 2014).

El contexto en que se engarza esta cita se refiere a cómo pueden afectar las nuevas formas de comunicación a la actividad política y, en particular, al uso de la red para la articulación de nuevos sistemas electorales o como agente de renovación de los actuales modelos democráticos. Tras el análisis de varias investigaciones recientes consignábamos que "la red no cambia la sustancia de la democracia representativa, pero sí sus formas y procedimientos...que no varíen las nociones fundamentales es compatible con que la transmisión horizontal y el intercambio interpersonal de las funciones de emisión, reproducción y recepción de contenidos quede al alcance de las relaciones interpersonales". El énfasis del cambio se centraba en la inusitada expansión que las relaciones interpersonales han experimentado a través de la red. Además de la bibliografía procedente de varios trabajos de investigación sobre el uso político de las redes (un ejemplo: Cebrián, Vázquez y Olabarrieta, 2013), examinamos diversas fuentes estadísticas para concluir que:

"las redes son "sociales" mas que "políticas"; que los usuarios dedican el tiempo principalmente a establecer "relaciones personales", al entretenimiento o al ocio, y en poca medida a la participación; que el "activismo" entre los jóvenes no describe una tendencia, sino una circunstancia, y que, en el concepto de participación política, cabe tanto usar las redes al servicio de procedimientos democráticos como antidemocráticos" (Núñez Ladevéze, Álvarez de Mon y Núñez Canal).

Tales apreciaciones tenían por fin comprobar algunos diagnósticos sobre el alcance de los cambios que pueden producirse en la democracia por las posibilidades que abre la red para establecer relaciones personales a distancia entre representantes y representados. En este texto tratamos de precisar un aspecto complementario: está por ver hasta qué punto afecta a la producción de la industria cultural el intercambio de las funciones emisora y receptora. En el trabajo anterior señalábamos que lo más significativo del cambio procede de que abre un horizonte inesperado a las relaciones "cara a 
cara". Hasta ahora estaban conceptualmente circunscritas a un tipo de comunicación entre un limitado número de personas en un espacio físicamente compartido por los sujetos de la comunicación. Así fue mientras no existió internet. Los estudios clásicos que investigaron la influencia personal no pusieran en duda estos límites espaciales (Katz y Lazarsfeld, 1979) ${ }^{1}$. La novedad ha revolucionado el panorama de las relaciones. Ofuscado por el crecimiento de las redes sociales, Rifkin ha llegado a escribir que "quizás el descubrimiento más importante sobre el uso de Internet es que la red, más que los encuentros sociales 'cara a cara', parece sacar a la luz el 'verdadero yo' de la persona" (Rifkin, 2010: 567).

Precisemos nuestra hipótesis: lo que en este trabajo asumimos, sobre la base del antes citado, es justamente lo contrario de lo que supone Rifkin: la red no produce el efecto purificador de sacar a relucir el "verdadero yo" de la persona mejor que los encuentros físicos "cara a cara", lo que hace posible son encuentros 'cara a cara' sin proximidad física. A esto nos referíamos cuando observábamos que "los cambios no afectan a la sustancia antropológica". La novedad no consiste en que el uso de Internet contraponga las relaciones 'cara a cara' a las establecidas en red. En nuestro planteamiento, Internet amplía el ámbito designativo de las relaciones personales "cara a cara" al desvincular esa relación de un espacio limitado por la contigüidad espacial de los actores. No hace más ni menos patente el verdadero yo de la persona, como tampoco modifica la sustancia de la democracia ya que no altera el sustrato antropológico de la condición social. Hace tan accesible a distancia la integridad personal como la hace la cercanía, aumentando tanto las posibilidades de autenticidad como de disfraz. En lo que sigue nos proponemos precisar este planteamiento mostrando cómo "la economía social de los procesos comunicativos" incide en el sistema productivo de la industria cultural.

\section{De la crítica a la cultura de masas a la cultura digital}

Lo que se conoce como cultura de masas aparece cuando la tecnología de la comunicación se destina a la producción en serie de bienes culturales manufacturados. La industria del "entretenimiento" se inicia con la imprenta, pero son, la rotativa primero y la radio después, los instrumentos que permiten difundir los productos del conocimiento y la cultura, hasta entonces reservados a círculos socialmente restringidos de una población indiscriminada (Burke y Briggs, 2002: 81, ss. y capítulos finales). La tecnología de la comunicación produce el salto cualitativo de abrir los bienes culturales a la participación generalizada. La contrapartida es que la producción en serie suscita una masiva convergencia en la trivialidad. Se comprende que los críticos de la cultura de masas centraran inicialmente su atención en la radio, el cine y los semanarios, pues la producción en serie del entretenimiento colectivo con fines comerciales se fragua desde que la tecnología hace posible la fabricación seriada de copias impresas y de receptores de audio ${ }^{2}$.

Según el funcionalismo sociológico de la posguerra, el desarrollo de los medios de comunicación propició una industria cultural orientada a procurar a la población una "cultura de masas" mediante el consumo de productos destinados al entretenimiento 3 . Adoptada esta perspectiva, la explotación comercial de la televisión no aportó novedad, 
sino que contribuyó a la expansión del proceso amplificando los efectos masificadores de la gran industria destinada a la explotación del ocio. Es interesante subrayar que no fue la televisión lo que centró la atención de quienes se ocuparon de analizar los rasgos que definen a la cultura de masas. La explotación comercial de las grandes audiencias se centra originariamente en la radio y los estudios preliminares sobre la manufactura industrial de productos audiovisuales viene ligada a la filmografía. Las novelas por entregas en diarios y semanarios y los seriales radiofónicos se anticiparon al género de las series televisadas. La novedad se limitó al cambio de soporte. La observación viene a cuento para comprender que la explotación de la televisión como industria de entretenimiento masivo solo significó una modificación acumulativa, pero no supuso un salto cualitativo ni una discontinuidad en la relación entre productores de la industria cultural y receptores de los productos manufacturados.

Los estudiosos coincidían en que la industria cultural propició un denominador común, desvinculado de la cultura auténtica, una cultura aparente y vacía de contenidos. Se la llamó "cultura de masas". Antes de la televisión, la industria suministraba ya contenidos a un consumidor pasivo (Lazarsfeld y Merton, 1948) ${ }^{4}$, al que también se le calificó de unidimensional ${ }^{5}$. Describen su posición como la de mero sujeto receptor limitado a aceptar o rechazar lo que se le ofrece. Es interesante retener que la crítica de la industria cultural señalara que la causa de la separación entre "cultura de masas" y "cultura auténtica" tenía su origen en que la "pasividad" del destinatario venía determinada por el carácter "unidireccional" de la relación comunicativa: la industria productora monopoliza la función emisora y el destinatario de la comunicación queda reducido a consumidor pasivo. Presuponían que si el destinatario pudiera intercambiar su función receptora por la emisora o, al menos, personalizar sus preferencias, quedaría liberado de las constricciones del capitalismo cultural. Alguna de las advertencias de estos pioneros de la crítica a la sociedad de masas se centró en que:

"la radio, democrática, convierte a todos en oyentes, para remitirlos autoritariamente a los programas, entre sí iguales, de las diversas emisoras. No se ha desarrollado ningún sistema de réplica, y las emisiones privadas están condenadas a la clandestinidad... cualquier huella de espontaneidad del público en el marco de la radio oficial es dirigido y absorbido" (Adorno y Horkheimer, 1996:167).

Simplificando, la crítica a la "industria cultural" de Adorno y Horkheimer se centraba en que el capitalismo no desarrollaba "ningún sistema de réplica", bloqueaba la "espontaneidad del público", imponía a la audiencia la función de "oyente", y la sometía "autoritariamente a los programas entre sí iguales". Con la reproducción seriada de bienes de consumo cultural y el acceso radiado o escrito a los espectáculos multitudinarios "las masas tienen lo que desean y se aferran obstinadamente a la ideología mediante la cual se les esclaviza... La industria se adapta a los deseos por ella misma evocados (Id. 178)". El desarrollo de la televisión no hizo más que acentuar los motivos de la reprimenda. El énfasis enraizaba en la expresión "masa". La descripción de la tecnología como mass media respondía a esa apreciación. En la Dialéctica de la Ilustración (como en El hombre unidimensional) no es la persona la que necesita lo que se le ofrece, no es el individuo quien desea lo que desea, es la persona o el indi- 
viduo en tanto aparecen como meros elementos de un sujeto colectivo descrito como "masa", alienado por la estructura económica del capitalismo democrático.

Tras el desarrollo de la tecnología comunicativa el reproche pierde su fundamento: no es sostenible que la carencia de un "sistema de respuesta", la falta de "espontaneidad del público", el sometimiento de la audiencia a la función de "escucha", la imposición "autoritaria de los programas" tuviera que ver con un designio inherente al capitalismo industrial. En la era del acceso ilimitado a la información, del intercambio universal de productos y de las relaciones "cara a cara" simultáneas, ilimitadas y a distancia, no se puede mantener que "la industria se adapta a los deseos por ella misma evocados"6.

\section{El nuevo escenario de la personalización del mercado}

Los críticos presumieron que los gustos de los consumidores estaban determinados por su reducción a la función receptora y la monopolización de la emisora por los propietarios de la industria cultural. Se sugería que si pudieran pasar a ser productores o emisores la cultura se transformaría. Con la nueva tecnología las funciones emisora y receptora son por fin intercambiables, las relaciones "cara a cara" no quedan restringidas a un reducto físico, pueden establecerse a distancia, las relaciones personales se difunden simultánea e ilimitadamente. El espacio de la red digital permanece abierto a la iniciativa del usuario, el cual no queda condicionado por los requerimientos, tan accesibles y abundantes de la oferta, que quedan indeterminados ante las innumerables opciones del consumidor (Rifkin, 2000) ${ }^{7}$. Ya no puede sostenerse que la asimetría del proceso comunicativo determine la preferencia cultural predominante. Será el arraigo del usuario en un mundo de la vida, que se ha ido constituyendo en un entorno familiar, escolar y profesional concreto, abierto ahora a percepciones más etéreas y diluidas a través de la red, de donde proceden la matriz de prescripciones que motivan las elecciones selectivas de la demanda. En la apertura de ese panorama, cada consumidor puede gestionar con autonomía sus intereses subjetivos. Autonomía relativa, condicionada por las determinaciones previas que han contribuido a constituir una identidad concreta, y autonomía abierta a todos los intercambios imaginables a través de la dispersión virtual.

A partir de internet las relaciones personales pueden realizarse a distancia y simultáneamente entre un número ilimitado de usuarios. Esta ubicuidad de las relaciones desdibuja algunas diferencias descriptivas establecidas por la sociología precedente. El concepto de "público" o de "audiencia" ya se ha puesto en entredicho por inaplicable a las nuevas prácticas del periodismo en Internet (Deuze y Fortunati, 2010). Las relaciones personales en una red social digital pueden aproximarse a las que postularíamos como rasgos de una muchedumbre o aglomeración virtual ${ }^{8}$. La zona de paso se vuelve tan fluida que justifica la metáfora de que la red promueve relaciones "líquidas". Se licúan los contrastes en que se basaban las distinciones sobre grupos sociales establecidas en la sociología del siglo pasado. Esta amorfia se manifiesta también en la producción y difusión de manufacturas audiovisuales.

Nos interesa comprobar si en este nuevo escenario los datos permiten atisbar que se producen modificaciones significativas en la demanda de bienes culturales, si la 
uniformidad de las aficiones y gustos culturales, que desde el surgimiento de la radio y la prensa amarilla fueron continuas, queda quebrantada por la capacidad de los consumidores para personalizar el producto o si la interacción entre oferta y demanda entraña alguna discontinuidad apreciable respecto de la dominante en la cultura de masas precedente. Aunque los indicadores pueden ser en algunos casos reduccionistas, ya que no suelen dar cauce a tipos de uso distintos de los comercialmente significativos ${ }^{10}$, esa limitación puede completarse con encuestas específicas ${ }^{11}$. Para esta indagación no es necesario, pues los datos de las fuentes estadísticas disponibles dejan patente la tendencia global del uso de la red que nos proponemos estudiar y, por tanto, estas referencias son un instrumento idóneo para satisfacer ese interés cognoscitivo. Lo que importa es comprobar, mientras la progresiva expansión de las relaciones personales a distancia va difuminando diferencias entre tipos de relación personal y entre grupos sociales, si se altera la orientación de los hábitos o las actitudes de los usuarios respecto de las que conformaron las grandes audiencias televisivas en la sociedad de consumo de masas.

El cambio principal causado por la profusión de formas personales de participar como agente, y no mero receptor, del proceso comunicativo, se manifiesta en lo que se ha llamado "personalización en masa del mercado" de bienes y servicios. La actividad empresarial ha respondido a esta "personalización" de diversas maneras que han adaptado la estrategia de la producción buscando nuevas formas de relación con el cliente, como la creación de cadenas de conocimiento y de colaboración en la red (Choudhary, Harding, Camarinha-Matos, Koh y Tiwari, 2013). Pero las consecuencias culturales relevantes se producen en otra zona distinta del mercado de bienes y servicios, en la "personalización de la industria cultural". Lo que las estadísticas reflejan son las tendencias marcadas por la urdimbre de las elecciones personalizadas. Qué corrientes predominan en la promiscuidad de los gustos, en la multiplicación de los intercambios, en la disparidad de las opiniones, en la fragilidad de los esquemas, en la disparidad de los criterios que pueden circular, para rechazarse o compartirse, impugnarlos o rebatirlos. Al entramado de gustos y opiniones personalizados, corresponde toda suerte de requerimientos para satisfacción de cualquier clase de deseos, desde los más exquisitos a los más burdos y de toda especie de apetencias, desde las más previsibles a las menos imaginables. Según nuestra hipótesis que lo exquisito sea selectivo y lo burdo, mayoritario, es un asunto que hiende en la antropología cultural independientemente de lo que acontece en una cultura específica.

De los participantes en el proceso sobreviven los que adaptan sus estrategias comunicativas al marco de condiciones que exige incorporarse a la red. No es difícil comprobar que, en lo que atañe a la oferta de productos audiovisuales complejos, esta adaptación al flujo comunicativo no modifica la estructura empresarial, aunque mantener la eficacia frente a los nuevos competidores obligue a renovarse sumándose a la procesión. Cuanto mejor se cumpla esa condición de adecuación a la nueva tecnología, más seguro es el mantenimiento de la competencia adquirida en la producción de bienes y servicios. Quienes merodean por las redes personalizando la información y los productos audiovisuales actúan más como intermediarios del gusto en la formación de opiniones que como productores o competidores de la programación audiovisual o cinematográfica. 


\section{Flujos de la demanda en la red}

Anticipemos que los datos utilizados en este trabajo solo se refieren a España. Eso no impide comprender los muchos motivos para sostener que el diagnóstico va mas allá de este ámbito de referencia. Independientemente del grado en que puedan o no ser extrapolables a otros países, no cabe dudar de que puedan servir de pauta comparativa para apreciar cómo se manifiestan estas tendencias en otros entornos, determinando un patrón que permita señalar líneas de desvío o de coincidencia, rangos de variación o diferencias en la distribución. En todo caso, los impulsos que dirigen el cambio no son privativos, son comunes a las democracias occidentales y, tal vez, transferibles a sociedades que no lo son. No es posible participar en la aldea global sin adaptarse a los procesos que la promueven. Internet es un medio, una tecnología y un conector universal, pero también lo son el mercado global del que forma parte, las transmisiones radiadas o televisadas, los enlaces de Google o los itinerarios del correo electrónico. No hay fronteras para la exportación y transferencia de los contenidos. Las mismas series, los mismos esquemas de programación, los mismos modelos, los mismos anuncios publicitarios se repiten y renuevan formando parte de los alientos de un mercado unitario. La industria de la producción de entretenimiento no conoce límites geográficos ni se concentra en satisfacer apetencias locales. El fenómeno que Nielsen calificó en 2012 de "uso social de la televisión" lo detecta Telefónica espontáneamente reproducido en España en 2013. Los sistemas de clasificación son análogos. La 1lamada sociedad de la información responde a un estímulo común. Si la crítica de la "industria cultural" se refería indistintamente a las democracias occidentales, las corrientes que impelen la era digital forman un tejido más tupido todavía que el de la cultura de masas predecesora.

Descendiendo al detalle de los datos, contra lo que cabría esperar del incremento del uso de internet que refleja la Encuesta de Equipamiento del INE ${ }^{12}$, el consumo diario de televisión ha subido hasta 246 minutos de promedio diario en 2012 y 244 minutos en 2013. Igualmente ha ocurrido con las audiencias a pesar de la expansión de los videojuegos, el aumento de uso de los móviles y el desplazamiento a otros canales de acceso a través de la red ${ }^{13}$. En el cuadro se puede comprobar el progreso del consumo televisivo en los últimos veinte años.

Gráfico 1: progresión del consumo diario de televisión convencional en minutos por día y media de consumo (218 mins). Elaboración propia a partir de Análisis televisivo 2013. Barlovento comunicación 14

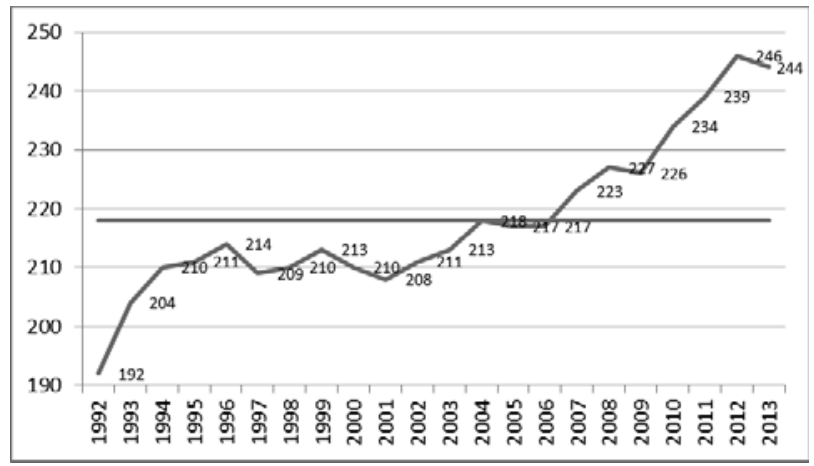


Basta este dato para mostrar que la red no ha contribuido a cambiar las actitudes en lo relativo a la estratificación de la demanda cultural televisiva. En la sociedad de las transacciones virtuales, como en la anterior de consumo de masas, que la calidad es inadaptable a la cantidad sigue formando parte de la experiencia cotidiana. Lo exquisito es objeto de una selección cualitativa mientras el gusto dominante satisface sus deseos en el denominador común de la trivialidad ${ }^{15}$. El consumo de la producción convencional de televisión no solo no ha sufrido mermas por las posibilidades abiertas al destinatario para "personalizar" su producto, sino que ha aumentado. La tendencia a la uniformidad permanece dentro de la pesquisa aleatoria de valores culturales y morales. Tampoco la demanda ha alterado los flujos de producción de contenidos. Como dice Rifkin, las empresas disponen de recursos económicos y tecnológicos que no están al alcance del aficionado. La interactividad se adapta a esa estructura de la industria de la producción audiovisual que no parece haber sufrido más alteraciones en este punto de las relaciones entre oferta y demanda de consumo cultural que la de servirse de las posibilidades de una relación interpersonal para facilitar la selección de productos a la carta y una mayor capacidad de adaptación a los gustos de una audiencia que tiende a fragmentarse (Vaca Berdayes, 2009).

La incorporación de la TDT y el afianzamiento de las autonómicas ha consolidado esta fragmentación sin que ello haya interferido la estrategia de la programación. Explica en parte que aumente el promedio diario del consumo televisivo, el que el propio tráfico de las redes sociales contribuya a mantenerlo. El informe Nielsen de 2012 ha calificado de televisión social el progresivo aumento de usuarios que usan las redes para comentar programas de televisión mientras los ven ${ }^{16}$. Lo cual significa que las relaciones personales "cara a cara", a distancia -el "boca a boca", dice el informe- de un medio interpersonal, puede simultanearse e integrarse con el uso de un artilugio unidireccional como el receptor televisivo. Los datos del informe muestran cuan fácilmente se produce esta simbiosis entre un medio unidireccional y las relaciones interpersonales a distancia. Lo confirma el último Informe de la sociedad de la información:

“...un número cada vez mayor de usuarios utilizan otros dispositivos mientras ven la televisión, Internet desplaza a libros/periódicos como el uso simultáneo más habitual mientras se ve la televisión...está adquiriendo importancia el acceso a redes sociales y en general el compartir con otras personas (conocidas o no) lo que se está viendo en un momento concreto. Así, en España más de 2 millones de personas han realizado en alguna ocasión comentarios en Internet sobre el contenido que se encuentran visionando, lo cual supone un $10 \%$ del total de internautas. De esta forma el carácter social, que envuelve a la mayoría de las actividades de Internet también llega al consumo de contenidos audiovisuales (Fundación Telefónica, 2014: 64)

La variedad de procedimientos de tránsito no ha alterado la dinámica del mercado de los contenidos ni la dedicación del tiempo de ocio del consumidor. Así, pues, la estabilidad de las audiencias en la programación televisual es compatible con la variedad de artilugios con accesos personalizados a la programación y con la penetración de internet. La industria no ha tenido que cambiar los contenidos para satisfacer una demanda sin retroceso, aunque se hayan multiplicado los canales de difusión, reno- 
vado las técnicas de reproducción y aumentado las puertas de acceso. La orientación del gusto no ha variado tampoco con el cambio de la relación entre el consumidor y la oferta. Las audiencias siguen fieles al modo tradicional (llamémoslo así) de sintonizar directamente el programa a través de un televisor. Tal vez este tipo de audiencia haya llegado a su cénit en 2013, pues, como hemos visto en el Gráfico I, el consumo ha aumentado año a año hasta el 2012. Lo significativo es que esta fidelidad se mantiene a pesar de la multiplicación de canales y de artefactos (ordenadores, tabletas, móviles u otros tipos). En los datos del EGM puede comprobarse que la penetración de la televisión convencional sigue constante a pesar de la progresiva penetración de internet. La imparable renovación del utillaje electrónico en el ajuar no impide que la televisión sea prácticamente un doméstico universal ${ }^{17}$.

Gráfico 2: Equipamiento doméstico de TIC y de receptor de TV en los hogares y penetración de televisión e internet. Elaboración propia a partir de la Encuesta sobre equipamiento y uso de TIC en los hogares españoles, INE, 2013 y del EGM, 2013 ${ }^{18}$ :

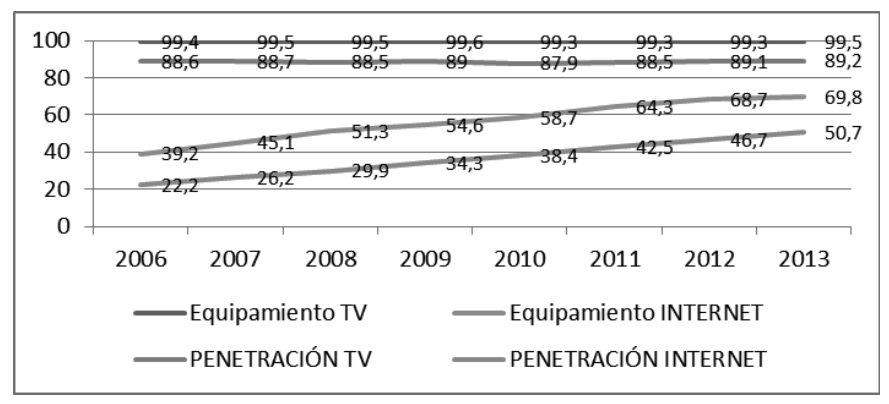

A efectos de nuestro enfoque llama la atención que a este equipamiento corresponda también un aumento continuado de la audiencia tradicional a pesar, como puede observarse en el gráfico, del estancamiento de la población desde el 2009 y del descenso poblacional en 2013:

Gráfico 3: Evolución de la población en azul y evolución de la audiencia televisiva en rojo (universo mayores de 4 años) en España del 2001a 2013.

Elaboración propia sobre datos del INE, 2013 y Barlovento, 2013:

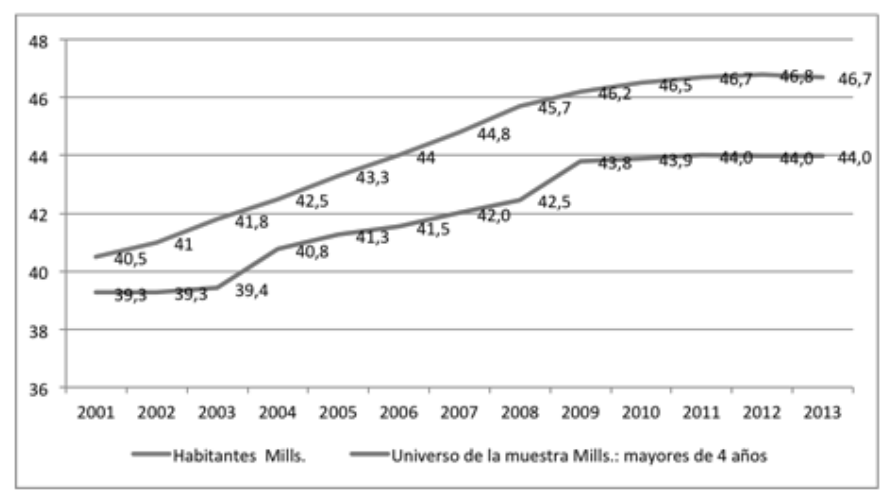


Tampoco la función publicitaria padece variaciones significativas, a pesar de que los canales de distribución de la publicidad se multipliquen. Al poder optar entre distintos itinerarios, la audiencia se fragmenta en los ramales de la circulación, pero el progresivo desplazamiento de la publicidad a la red no modifica que, en el punto de llegada, ejerza la misma presión sobre el mercado cultural, aunque siga una vía diferente ${ }^{19}$.

La comprobación de estos datos lleva a plantearnos un asunto más genérico sobre el sentido del cambio. Sin duda la revolución tecnológica introduce una nueva etapa en la historia de la comunicación. Pero ese reconocimiento no quita que el impulso renovador de la tecnología coexista con zonas muy apreciables de continuidad: la conectividad a distancia posibilita a todo usuario el acceso a toda fuente de información disponible, sí, pero no modifica la distribución social del conocimiento; las funciones emisora y receptora son intercambiables, sí, pero la producción audiovisual sigue en manos de grandes empresas; ambas posibilidades quedan en manos de la demanda al arbitrio de decisiones personales, sí, pero el interés se concentra en el uso social y el entretenimiento pasivo ${ }^{20}$.

Esta continuidad se puede apreciar en otras fuentes estadísticas. Según la encuesta del INE sobre equipamiento, la "participación en redes sociales" se ciñe sobre todo a relaciones genéricas: "el 64,1\% de los usuarios de Internet en los últimos tres meses (el 46,4\% de la población de 16 a 74 años) participa en redes sociales de carácter general como Facebook, Twiter o Tuenti, creando un perfil de usuario o enviando mensajes u otras contribuciones. Los más participativos son los estudiantes $(94,8 \%)$ y los jóvenes de 16 a 24 años $(94,5 \%)$... Por otro lado, el 14,6\% de los internautas en los últimos tres meses ha participado en redes de tipo profesional... Este porcentaje se eleva al $47,1 \%$ en los trabajadores relacionados con el sector TIC y alcanza el 29,3\% entre los titulados superiores" (INE, 2013) ${ }^{21}$.

En este contexto es relevante, y tiene valor para la confirmación del tipo de uso predominante, que el principal motivo para acceder a Internet desde los móviles sea "el entretenimiento"22:

Gráfico 4: uso del teléfono móvil en la red: Elaboración a partir de Google, ámbito España, 2013:

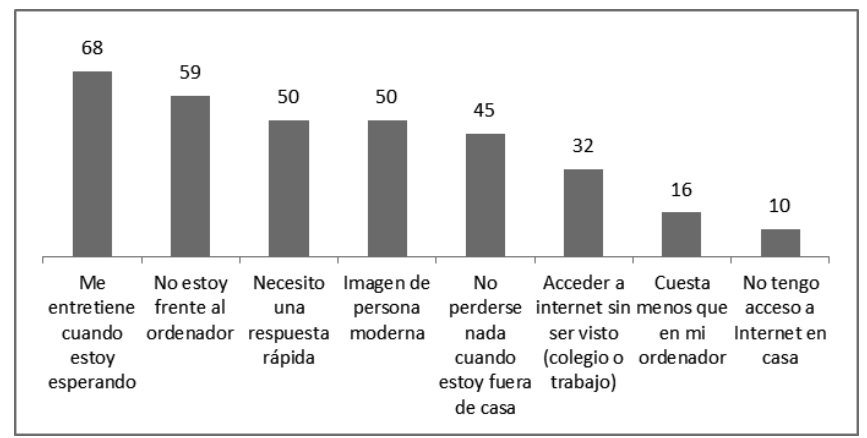


Cabría pensar que, al referirse estos datos, al promedio de la población española, pudieran no ser aplicables a las audiencias menores de 24 años, pues suele insistirse en que los jóvenes dedican menos tiempo a la televisión que los adultos, pero tampoco es el caso como se desprende del cuadro que incluimos a continuación en la que se observa que, si bien es cierto que el promedio de atención diaria aumenta correlativamente con la mayor edad, también es patente que el consumo de la población menor de 24 años permanece estable o aumenta ligeramente aunque disminuya la edad:

Gráfico 5: Consumo en minutos por persona y día en los últimos cinco años, promedios anuales por target de edad. Elaboración a partir de datos Kantar Media Audiences, 2014, http://www.kantarmedia.es/:

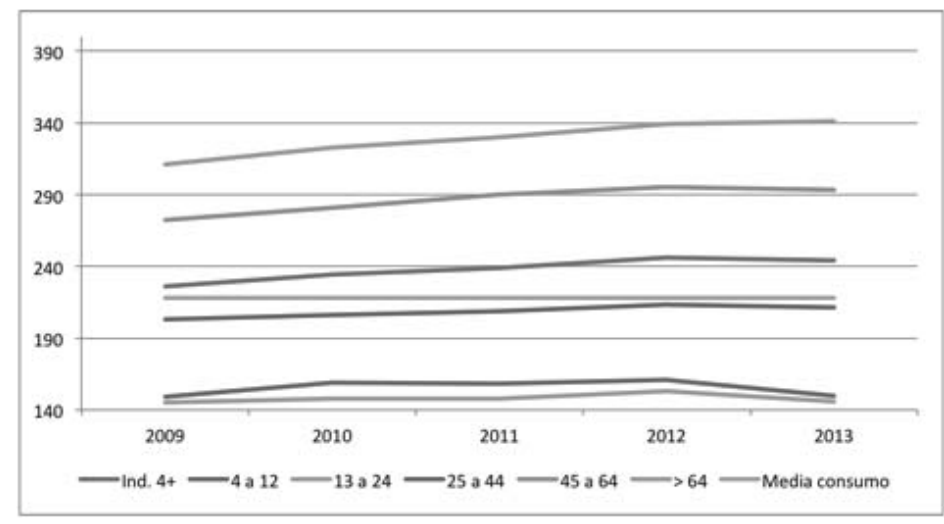

\section{Continuidad y discontinuidad en el cambio}

No estamos poniendo en duda la magnitud del cambio, sino tratando de precisar dónde hay que situar su impacto en la vida social. La gran innovación tecnológica sitúa a la sociedad del siglo XXI exactamente donde los críticos de la industria cultural advertían que no estábamos porque la estructura de la sociedad capitalista impedía que estuviera. Pero lo estamos gracias al impulso de esa industria puesta al servicio de un capitalismo, ahora no "tardío", ya postmoderno o digital. Si no había simetría en los papeles de emisor y receptor no era porque lo impidiera un designio inherente que retrajera al capitalismo de innovar donde pudiera fomentar ámbitos de interacción, sino porque la posibilidad de establecerlos aún no estaba al alcance de la explotación de la tecnología. La conclusión es que se juzgaba a una sociedad sobre un supuesto inaplicable. Ahora ya lo está, y no a pesar de, sino gracias al impulso de la tecnología promovido por la industria al servicio del capital.

A pesar de las importantes innovaciones tecnológicas que modifican las relaciones de los agentes del proceso comunicativo, no se aprecian signos de que se modifiquen la tendencia generalizada del gusto popular, tampoco la del sistema productivo ${ }^{23}$. Los datos confirman que los cambios en la tecnología de la comunicación no alteran los rasgos del capitalismo industrial: la tendencia hacia una estratificación del ocio correlativa a los procesos de formación de minorías en los distintos órdenes sociales. A través de la red, las preferencias selectivas de usuarios interactivos siguen la misma inclinación que distinguió a las tendencias culturales de la que procede la sociedad di- 
gital. La inclinación al entretenimiento es la constante entre los usuarios de la red, la misma que predominaba con los "oyentes" de la radio y con las audiencias del televisor. Se confirma el diagnóstico que a principios de siglo llevó a advertir que "en esta coyuntura, el capitalismo industrial está culminando su transición hacia un capitalismo cultural" (Rifkin, 2000, 91). El panorama de la producción audiovisual parece confirmar esa tendencia. El intercambio de bienes en la sociedad de consumo digitalizada no lleva a una revocación de la estructura del mercado de bienes o de servicios ni altera el proceso de estratificación del gusto, sino que conduce a una adaptación de los procedimientos comerciales a los nuevos cauces provistos por la tecnología, lo que se llama "comercio electrónico" (Fundación Telefónica, 2013: 32, 44 y 45$)^{24}$.

Se mantiene esa estructura del mercado cuando la innovación de los recursos y los procedimientos del tráfico mercantil consolida el respaldo de las estrategias publicitarias a las transacciones on line; mientras progresa la sustitución de actividades comerciales presenciales por operaciones virtuales en las compañías establecidas; con la aparición de centros exclusivamente dedicados al comercio a través de la red; si las grandes compañías fomentan esa adaptación para no quedar al margen de las nuevas oportunidades que ofrece; porque surgen nuevos tipos de negocio y de transacciones especializados en esas operaciones ${ }^{25}$. La multiplicación de actividades mercantiles virtuales y la adaptación del viejo tejido empresarial a los nuevos procedimientos para agilizar su gestión y ampliar su clientela muestran que la red actúa como un condicionante que exige la acomodación a un nuevo espacio, pero no determina un signo en las estructuras. El capitalismo permanece por su capacidad de adaptación a la capacidad de innovación y a los resortes que la propia industria capitalista pone en funcionamiento. De momento, cabe concluir que la tecnología de la comunicación fomenta la renovación, no entraña problema para la adaptación a los nuevos cauces, no implica la revisión del sustrato democrático. Ocurre como si al capitalismo de la revolución industrial suceda el capitalismo de la sociedad postindustrial y a éste el capitalismo de la sociedad digital. En lo relativo a la explotación de bienes destinados al consumo cultural la nueva tecnología acentúa las tendencias que arrastra, ahora no diseñada por la asimetría de la relación entre la oferta y la demanda que limitaba las posibilidades electivas. El intercambio se pliega más a los gustos personales del usuario. La orientación del gusto al entretenimiento se transmite de las audiencias de la cultura de masas a los ciudadanos digitales.

\section{Aspectos de la discontinuidad}

\subsection{La nueva cotidianidad de la proximidad 'cara a cara' a distancia}

Usando un registro metafórico, la red digital es en el lenguaje usual, una superficie "navegable"26. Donde no hay distancias, cercanía ni lejanía, todas las relaciones son equidistantemente próximas. Su peculiaridad consiste en que añade a la interacción cotidiana de las subjetividades una nueva cotidianidad superpuesta, más aérea e imprecisa, pero no menos presente y efectiva. Es la proximidad de un 'cara a cara' instantáneo, simultáneo y sin confines, que puede llegar a ser universal. 


\subsection{Dispersión de los fundamentos}

En la intersección virtual de las innumerables subjetividades que concurren en esa superficie, se fragua un magma neblinoso donde todos los gatos se hacen pardos y no resulta fácil distinguir la opinión fundada del infundio, el bulo o el rumor de la noticia verificada, las fuentes del saber de las contaminaciones ideológicas, la pretensión de racionalidad de la engañosa, la simplicidad del razonamiento de la demagogia simplificadora. La disparidad de puntos de vista y la abundancia de la información al alcance del consumidor puede coexistir con la precariedad de los fundamentos. Si la formación intelectual para separar el saber de la sinrazón puede quedar empantanada en esta mezcolanza, con igual o mayor motivo la conducta puede verse comprometida a optar entre la cooperación con el bien social, plegarse a la satisfacción del instinto o, en fin, saciar la voluntad de dominio abusando o aprovechando cualquier situación ventajosa.

\subsection{Responsabilidad de las autonomías personales}

En el espacio virtual donde todo es accesible y cada uno puede encontrar lo que desea cuando lo busca, saber es saber discernir y cada sujeto del proceso es responsable de lo que encuentra. Es su libertad de elección la que principalmente determina la búsqueda. Esto es una novedad cuya diferencia entra a trámite cuando nos ocupamos de la inquietud de la crítica cultural por el devenir de la razón en la sociedad digital capitalista. Cada usuario pone en circulación sus criterios, sus gustos y selecciona los bienes que le interesan. Su selección expresa una conducta que no responde a un imperativo racional (si es que tal asociación de palabras no expresa un oxímoron), es una decisión de naturaleza moral. Es la fuerza de la voluntad para cumplir o desentenderse de los principios normativos socialmente establecidos, no la abstracta directriz de la razón, la que rige las decisiones en el ámbito normativo. El criterio puede estar claro, incluso aceptar su evidencia, pero lo decisivo es que de su inteligibilidad no se deduce su cumplimiento. Cualquiera que sea el juicio que se tenga sobre la conveniencia o inconveniencia de la decisión adoptada, esta es un acto que pone en jaque la responsabilidad personal, no un imperativo dialéctico.

\subsection{Problematicidad de una moral dominante}

Corolario de la autonomía electiva del usuario es que las fuentes de la moralidad dejan de emanar de la supremacía jerárquica de un grupo social sobre otros. En los vericuetos de la red se diluye la presión mediante la que la estratificación social impone rangos de valor y de autoridad ${ }^{27}$. La vieja cantinela de que la moral dominante es la expresión de la clase dominante pierde punto de apoyo cuando la moral dominante queda regulada por el acceso irrestricto a la red $^{28}$. Si todas las opiniones son libres de exponerse, pueden reconocerse como equivalentes. La tarea de establecer distinciones queda transferida al usuario que sufrirá las consecuencias de su elección. En la dilucidación de si un criterio es fundado o arbitrario, si procede del profesional o del oportunista, si enuncia la opinión del experto o la del ignorante, si responde a un gusto selecto o vulgar, si es solvente o estólido, cada palo debe aguantar su vela. La estratificación de la credibilidad, la adjudicación de prestigio y la confianza en la opinión 
ajena proceden de la interacción (Hindman, 2009) ${ }^{29}$. Cuando esta diversidad fluye fuera de los procesos institucionales socialmente establecidos, y las administra cada uno a su conveniencia, como ocurre en los entresijos de la red, resulta problemático apreciar qué conjunto de prescripciones merece ser reconocido como expresión moral de una clase dominante.

\subsection{Hacia nuevos procesos regulatorios}

De esa turbulencia surge la necesidad de discernir entre lo beneficioso y lo perjudicial, de segregar lo útil de lo inservible, de separar lo solvente de lo inmotivado, porque es necesario orientarse en el magma de una oferta ilimitada donde todo está potencialmente al alcance de cualquiera. La exactitud, la precisión y el rigor serán más cotizados cuanto menos discernibles. La protección del indefenso de la algarabía pasa a ser una preocupación institucional prioritaria ${ }^{30}$. Cuando todo aparece mezclado y se hace indistintamente accesible, surge con vigor el interés por salvaguardarse de los riesgos de resultar vulnerables a un tráfico desordenado, sin reglas, y de renovar procedimientos de regulación que prevengan de los abusos y excesos de esta profusión.

\section{Conclusiones}

Decía Daniel Bell que determinar el sentido del cambio era el principal problema de la sociología. Este trabajo se ha ocupado de un aspecto específico de este tema genérico. Hemos advertido pautas de continuidad con la sociedad de consumo precedente: los procedimientos de acceso a la producción cultural no alteran la tendencia anterior del mercado de los contenidos. El entretenimiento masivo y el aumento de las audiencias convencionales es compatible con la personalización del uso de internet. Predomina entre los usuarios de la red la misma inclinación que preponderaba entre los "oyentes" de la radio y las audiencias televisivas. Se confirma el diagnóstico que a principios de siglo llevó a advertir que "en esta coyuntura, el capitalismo industrial está culminando su transición hacia un capitalismo cultural" (Rifkin, 2000, 91). Las relaciones personales "cara a cara" a distancia se amalgaman con la televisión unidireccional para dar lugar a la nueva forma de participación de la "televisión social".

La principal discontinuidad es la proximidad a distancia de las relaciones personales a través de la red, el acceso sin desplazamiento a toda fuente de información. En el espacio virtual, donde todo es accesible y cada uno puede encontrar lo que desea cuando lo busca, saber es saber discernir. Cada sujeto navega con autonomía y bajo su responsabilidad, porque es su libertad de elección la que principalmente determina la búsqueda y el encuentro.

Cabría sostener, como colofón, que la continuidad de las viejas estructuras de la sociedad de masas en la sociedad virtual confirmaría la crítica de Adorno y Horkheimer si no fuera porque la propia crítica, vista al cabo del tiempo, desmiente su idoneidad. El diagnóstico de que "la industria cultural defrauda continuamente a sus consumidores respecto a aquello que les promete" pone de manifiesto que, en aspectos no tangenciales, las pretensiones de los críticos al reducir la cultura de masas a una pescadilla que se muerde la cola, no hacían justicia a posibilidades de la interacción racional de las subjetividades puestas actualmente de manifiesto por la transformación de las re- 
laciones interpersonales en la sociedad virtual. Esto es independiente de que se mantengan o cambien las actitudes de los usuarios. Al transformarse la sociedad de masas en una sociedad virtual de relaciones "cara a cara" realizables simultánea e ilimitadamente a distancia, no se modifican las tendencias predominantes de la industria cultural predecesora. Tampoco significa que la crítica pierda su función correctora, sino que, al igual que tampoco los cien táleros en la faltriquera no se deducen del concepto de tálero (Emanuelle, 2003), la capacidad de transformación social no puede elaborarla la razón crítica a partir de sí misma sin incurrir en la falacia de predecir los hechos deduciéndolos de su pretensión de racionalidad.

\section{Referencias bibliográficas}

ADORNO, Teodoro y HORKHEIMER, Max (1947): Dialéctica del iluminismo. Fragmentos filosóficos. Buenos Aires, Editorial Sudamericana.

ADORNO, Teodoro y HORKHEIMER, Max (1998): Dialéctica de la ilustración. Fragmentos filosóficos. Madrid, Trotta, $3^{\mathrm{a}}$ ed.

AEACP (2013): “infoadex de la inversión publicitaria en España, 2013”. En: www.infoadex.es/InfoAdex_Resumen_Est_Inv_2013.pdf

BARLOVENTO COMUNICACIÓN (2013): Informe anual 2013. Disponible en: http://www.barloventocomunicacion.es/images/publicaciones/ANALISIS\%20TELEVISIVO\%202013.pdf

BAUMAN, Zygmunt (1999): Modernidad líquida. Buenos Aires, FCE.

BAUMAN, Zygmunt (2007): Miedo líquido: La sociedad contemporánea y sus temores. Barcelona, Paidós.

BAUMAN, Zygmunt (2007): Tiempos líquidos: vivir en una época de incertidumbre. Madrid, Lumen.

BURKE, Peter y BRIGGS, Asa (2002): De Gutenberg a Internet: historia social de los medios de comunicación. Barcelona, Taurus.

CEBRIÁN GUINOVART, Elena; VÁZQUEZ BARRIO, Tamara; y OLABARRIETA VALLEJO, Ana (2013): “¿Participación y democracia en los medios sociales?: El caso de Twitter en las elecciones vascas de 2012". Preprint. Castellón, Repositori Universitat Jaume I. DOI: http://dx.doi.org/10.6035/2174-0992.2013.6.4

CHOUDHARY, Alok. K.; HARDING, Jenny A.; CAMARINHA-MATOS, Luis M.; KOH, Lenny S. C; and TIWARI, Manoj K (2013): "Knowledge Management and Supporting Tools for Collaborative Networks". International Journal of Production Research, vol 51, Issue 7, pp. 1953-57.

CORREDOIRA, Loreto. y COTINO HUESO, Lorenzo (eds., 2013): Libertad de expresión e información en Internet. Amenazas y protección de los derechos personales. Madrid, CEPC.

DEUZE, Mark y FORTUNATI, Leopoldina (2010): “Journalism without journalist: on the power shift from journalists to employers and audiiences". In MEIKLE, 
Granham and REDDEN, Guy (eds.): News Online: transformations and Continuities. Basingstoke, Palgrave Macmillan.

EMANUELLE, Pietro (2003): Los cien táleros de Kant. Madrid, Alianza.

AIMC (2013): Estudio general de medios, 2013. En: http://www.aimc.es/-DatosEGM-Resumen-General-.html

FUNDACIÓN TELEFÓNICA (2014): La sociedad de la información. Madrid, Ariel y Fundación Telefónica. Disponible en http://www.fundacion.telefonica.com /es/index.htm

IAB (2013): IV Estudio anual de redes sociales, enero 2013. En: http://www.iabspain.net/wp-content/uploads/downloads/2013/01/IV-estudio-anual-RRSS_reducida.pdf

INSTITUTO NACIONAL DE ESTADÍSTICA (2013): Informe de equipamiento (Nota de prensa, 25 de octubre). En: http://www.ine.es/prensa/np803.pdf

KANTAR MEDIA AUDIENCIAS (2014): Informe 2014. En: http://www.kantarmedia.es/

KATZ, Elihu y LAZARSFELD, Paul F. (1979): La influencia personal. El individuo en el proceso de comunicación de masas. Barcelona: Hispano Europea (V. O. 1946).

LYONS, Andrew Frank (2011): Customer-Driven Supply Chains: From Glass Pipelines to Open Innovation Networks. Liverpool, University of Liverpool.

LYONS, Andrew C.; EVERINGTON, Lucy; HERNANDEZ, Jorge E.; LI, Dong; \& UM, Juneho (2012): "The application of a knowledge-based reference framework to support the provision of requisite variety and customisation across collaborative networks". International Journal of Production Research, pp. 1-15.

MARCUSE, Herbert (1969): El hombre unidimensional. Ensayo sobre la ideología de la sociedad industrial avanzada. Barceona, Seix Barral (V. O. 1954).

MARÍ, Víctor (2012): "Reflexión crítica sobre los indicadores utilizados para la medición de los usos sociales de Internet". Revista Venezolana de Información, Tecnología y Conocimiento, 9 (1), pp. 61-71.

MERTON, Karl \& LAZARSFELD, Paul (1948): "Mass Communication, Popular taste and Organized Social Action". BRYSON, Lyman (ed.): The Comunication of Ideas. New York, Harper.

NÚÑEZ LADEVÉZE, Luis (2014, en prensa): La identidad democrática. Madrid, CEPC.

NÚÑEZ LADEVÉZE, Luis y PÉREZ ORNIA, José Ramón: "Los gustos de la audiencia infantil y la programación televisiva" en REIS, $\mathrm{N}^{\circ}$ 99: 112-145; jul-sep. 2002. I.S.S.N.: 0210-5233.

NÚÑEZ LADEVÉZE, Luis y VÁZQUEZ BARRIO, Tamara (2008): "La información, la opinión y la editorial periodística" en Textual Visual Media. Revista de la Sociedad Española de Periodística, núm. 1, pp. 255-275. 
NÚÑEZ LADEVÉZE, Luis y TORRECILLAS, Teresa (2011): "El poder y la comunicación en la sociedad digital" en Correspondencias\&análisis, núm. 1, pp. 3548. Perú.

NÚÑEZ LADEVEZE, Luis; ÁLVAREZ DE MON, Ignacio; y NÚÑEZ CANAL, Margarita (2014, en trámite): "Relaciones digitales cara a cara y cambios democráticos en la red: tendencias en España".

OBSERVATORIO DE LAS COMUNICACIONES (2012): Informe anual de los contenidos digitales (ONTSI). En: http://www.ontsi.red.es/ontsi/es/estudios-informes/informe-anual-de-los-contenidos-digitales-en-españ-edición-2012

RIFKIN, Jeremy (2000): La era del acceso. La revolución de la nueva economía. Barcelona, Paidós.

RIFKIN, Jeremy (2010): La civilización empática. La carrera hacia una conciencia global en un mundo en prisión. Barcelona, Paidós.

SALVAT, Guiomar y SERRANO, Vicente (2011): La revolución digital y la sociedad de la información" Zamora, Comunicación social.

THOMPSON, John B. (1998): Los medios y la modernidad, Una teoría de los medios de comunicación. Barcelona, Paidós.

VACA BERDAYES, Ricardo (2009): Estudio del valor de la audiencia televisiva de dos cadenas españolas emergentes. El caso de Cuatro y La Sexta: 2005-2008. Tesis doctoral. Madrid, CEU.

\section{Notas}

1 Todavía en 1998 Thompson escribía que "cuando los individuos utilizan los medios de comunicación, se introducen en formas de interacción que difieren en ciertos aspectos del tipo de interacción cada-a-cara que caracteriza la mayoría de los encuentros de la vida cotidiana (cursiva nuestra). Son capaces de actuar para otros que están físicamente ausentes, o actuar en respuesta otros que están publicados en lugares distantes. De manera fundamental, el uso de los medios de comunicación transforman la organización espacial y temporal de la vida social, creando nuevas formas de acción y de interacción. Y nuevos modos de ejercer el poder, disociados del hecho de compartir un lugar común". (Thompson, 1998: 17). Thompson aún identifica "interacción cara-a-cara" con "encuentros de la vida cotidiana", pero el quid de nuestro punto de vista estriba en que es la noción de "encuentro en la vida cotidiana" lo que cambia cuando el encuentro puede ser virtual a distancia sin dejar de ser cara-a-cara y cotidiano.

2 "Film, radio y semanarios constituyen un sistema... Film y radio no tienen ya más necesidad de hacerse pasar por arte. La verdad de que no son más que un negocio les sirve de ideología... Se autodefinen como industria”. (Adorno y Horkheimer, 1996:165-213).

3 Las expresiones "industria cultural" y "cultura de masas" fueron acuñadas por Adorno y Horkheimer en Fragmentos filosóficos, edición multicopiada en 1944, publicada en 1947. La editorial Sudamericana la tradujo con el título de Dialéctica del iluminismo. La edición de Trotta de Dialéctica de la Ilustración señala alguna variación de expresiones que en 1944 aparecían como "cultura de masas" y en 1947 como "industria cultural". La noción de "cul- 
tura de masas" se generaliza a partir de la publicación de Comunicación de masas, gusto popular y acción social organizada, por Merton y Lazarsfeld en 1948. "La gente tiene más tiempo libre. Tiene, ostensiblemente, mayor acceso a la herencia cultural Y, ¿qué uso hace de este tiempo no hipotecado, tan trabajosamente obtenido para ella? Escucha la radio y va al cine. Estos medios masivos de comunicación parecen haber burlado a los reformadores, en cierto modo, el fruto de sus victorias. La lucha por la libertad, el tiempo libre, la educación popular y la seguridad social fue conducida en la esperanza de que, una vez liberada de yugos opresivos, la gente aprovecharía los grandes productos culturales de nuestra sociedad".

4 “...transformando inadvertidamente las energías de los hombres de participación activa en saber pasivo..."

5 Cfr., El hombre unidimensional. Ensayo sobre la ideología de la sociedad industrial avanzada (MARCUSE, 1968). Ni en esta obra ni en Eros y civilización, trata de forma directa el tema de la industria cultural. Las escasas referencias responden a la idea de la cultura de masas unidireccional: "nuestros medios de comunicación de masas no tienen dificultades para vender los intereses particulares como si fueran los de todos" (19) "La libertad individual significaría la restauración del pensamiento individual absorbido ahora por la comunicación y adoctrinamiento de masas" (34). La objeción de que "damos demasiada importancia al poder de adoctrinamiento de los mass media...no es válida (porque) el precondicionamiento no empieza con la producción masiva de la radio y la televisión. La gente entra en esta etapa ya como receptáculos precondicionados...para la preservación del 'sistema establecido'.... ¿Se puede realmente diferenciar entre los medios de comunicación de masas como instrumentos de información y diversión y como medios de manipulación y adoctrinamiento?" (38-39)..."Este tipo de bienestar, el de la superestructura productiva...impregna a los 'mas-media' que constituyen la mediación entre los amos y sus servidores" (115). Excepto la referencia al "precondicionamiento" todas las demás observaciones quedan fuera de trámite con el surgimiento de las relaciones personales a distancia. En cuanto al "precondicionamiento" ha experimentado tal transformación con la convergente multiplicación de mundos de la vida en el espacio virtual y en el real, que no podrían entenderse hoy "receptáculos precondicionados para la preservación del sistema".

6 Id, 178. Como muestra de observaciones caprichosas valga esta cita: "el pato Donald en los dibujos animados como los desdichados en la realidad reciben sus puntapiés (sic) a fin de que los espectadores se habitúen a los suyos" (Id. 183).

7 Rifkin matiza que "a pesar de que internet y el ciberespacio ofrece a los consumidores individuales cierto poder de contravigilancia y permite la interactividad, la empresa sabe bastante más sobre el cliente que la información que este tiene sobre ella. Las reglas de juego de este nuevo mercado electrónico todavía siguen favoreciendo a las empresas" (66).

8 "Internet está convirtiendo el mundo en una gigantesca ágora pública en la que, literalmente, miles de millones de personas pueden conectarse, colaborar y crear un valor añadido conjuntamente en tiempo real" (Rifkin, 2010: 534).

9 La metáfora de la "liquidez" fue puesta de relieve por Zygmunt Bauman en Modernidad líquida, 1999. A esta obra siguieron otras donde en el propio título se utiliza el término "líquido" para expresar rasgos de esta nueva modernidad. Bauman no vincula expresamente el rasgo de "liquidez" al condicionamiento de la red, sino que se refiere críticamente a distintos aspectos de la postmodernidad. Como ocurre con toda metáfora brillante, esta tiene el valor de anticipar el sentido del cambio. La idea de "modernidad líquida" ha pasado a la de "democracia líquida". 
10 Algunas propuestas para la revisión de los indicadores parten de la toma de partido para "la medición de los usos y estrategias de apropiación de Internet por parte de la ciudadanía" (Marí, 2012). Resulta curioso que se ponga de ejemplo a la Fundación Telefónica cuando se cita como fuente de autoridad al profesor Bustamante, coordinador de la revista Telos, que edita dicha Fundación para comentario de sus informes. En Núñez Ladevéze, Álvarez de Mon y Núñez Canal, 2014, se comenta bibliografía que confirma que "la red no ha contribuido a que aumente la participación ni el interés por la política".

11 Así se hizo en el trabajo anteriormente citado.

12 http://www.ine.es/prensa/np803.pdf

13 Según el informe de 2013 sobre Sociedad de la información "hace tiempo que televisión perdió el monopolio del visionado de contenido multimedia al entrar el ordenador personal... por otro lado, el ... número de dispositivos con pantalla conectados a Internet no ha hecho más que crecer... ya que el $64 \%$ de los usuarios de smartphone visionan contenidos de esta naturaleza y el $41 \%$ acceden mediante navegación Web... Ambos fenómenos han contribuido a dibujar un nuevo escenario... el usuario puede acceder al contenido multimedia desde cualquier lugar y... el consumo pasa a ser un acto individual... Todo ello ha supuesto un importante incremento de visionado de los canales de televisión vía on line.” En este escenario, aparentemente adverso, aumenta el consumo de programas de televisión por el canal convencional. En cuanto al uso "individual" véase en el texto (nota 12: instituto Nielsen) la referencia al nuevo fenómeno de la "televisión social".

$14 \mathrm{http} / / / \mathrm{www} \cdot$ barloventocomunicacion.es/images/publicaciones/ANALISIS\%20TELEVISIVO\%202013.pdf

15 Merton y Lazarsfeld lo denominaron “disfunción narcotizante” en 1948. “...la disfunción narcotizante de los medios masivos de comunicación. Se la denomina disfuncional en vez de funcional, basándose en la presunción de que no corresponde al interés de la moderna sociedad compleja tener grandes masas de la población políticamente apáticas e inertes. ¿Como actúa este mecanismo no planificado?... Se sugiere... que este vasto aprovisionamiento de comunicación no suscite sino una preocupaci6n superficial sobre los problemas de la sociedad, y de que tras esta superficialidad se oculte con frecuencia una apatía de masas."

$16 \mathrm{http} / / / w w w . s l i d e s h a r e . n e t / r o s a b e r m e j o / t h e-s o c i a l m e d i a r e p o r t 2012-n i e l s e n$

17 En 2013 la penetración de televisión era del 89,2\% mientras que la de Internet era el 50,7\%. No importa tanto la diferencia, sino que la progresiva implantación de la red no interfiere en la penetración del televisor.

18 Equipamiento en porcentajes de televisión y conexión a Internet y penetración uso del día de ayer de televisión e Internet.

19 "La migración del ocio hacia el consumo de contenidos digitales ha favorecido el crecimiento de la facturación del sector, que en 2010 alcanzó en España los 9162M€, un 14,1\% más que en 2009...A nivel mundial, en 2010 el mercado de medios y entretenimiento volvió a la senda del crecimiento, alcanzando un volumen de negocio de $1,03 \mathrm{~B} €$, un $2,7 \%$ más que en 2009. De ellos, el 26,1\% de la facturación total corresponde a contenidos digitales, que lideran el crecimiento del mercado de medios y entretenimiento, entre los que destacan el acceso a Internet". Cfr. Estudio infoadex de la inversión publicitaria en España, 2013.www.infoadex.es/InfoAdex_Resumen_Est_Inv_2013.pdf

${ }^{20}$ Los datos estadísticos señalan que a la pregunta de ¿con qué frecuencia realizas el tipo de actividad en redes sociales? los usos preferentes consisten en enviar mensajes muy fre- 
cuente o frecuentemente; en segundo lugar seguir la actividad de mis contactos, en tercer lugar ver videos u oír música, seguido de chatear, publicar contenidos. El "comentario de actualidad" ocupa el sexto lugar. IAB, IV Estudio anual de redes sociales, enero 2013. http://www.iabspain.net/wp-content/uploads/downloads/2013/01/IV-estudio-anualRRSS_reducida.pdf

21 Aunque estos datos confirman el progreso de implantación de la sociedad de la información en nuestro país, queda todavía casi diez puntos por debajo de la media europea.

22 La sociedad de la información en España, 2013.

23 Rifkin (2010) expone un pronóstico correctivo: "los mercados son modelos de operación lineales, diferenciados y continuos... El tiempo transcurrido entre la finalización de un intercambio y la introducción del siguiente representa la productividad perdida y el coste añadido... hacen obsoletos a los mercados... las nuevas tecnologías de las comunicaciones y de la información no son lineales, sino cibernéticas. Permiten una actividad continuada a lo largo de amplios periodos de tiempo...".

24 Para la distribución del consumo de contenidos digitales en España, el Informe anual de los contenidos digitales (ONTSI) http://www.ontsi.red.es/ontsi/es/estudios-informes/informeanual-de-los-contenidos-digitales-en-españ-edición-2012

25 Cfr. el Estudio infoadex de la inversión publicitaria en España, 2013.

26 "Desplazarse a través de una red informática" 5. DRAE, $22^{a} \mathrm{ed}$.

27 "La forma no jerárquica que la generación del milenio tiene de relacionarse entre sí y con el mundo a través de la red..." (Rifkin, 2010: 534)

28 Para una visión crítica aplicada a la sociedad de la información para la que la eficacia de las nuevas tecnologías queda mediatizada por un proceso de mercantilización, cfr. Salvat y Serrano, 2011.

29 En su estudio Hindman (2009) concluye que si se entendiera por democratización digital que la red conceda la palabra a quienes no la tienen, el hecho es que la selección de blogs políticos que reciben mas visitas en Estados Unidos muestra que corresponden a una minoría de académicos y profesionales. Para un estudio en España sobre el proceso de asimilación de los géneros periodísticos por los blogs cfr. Herrera, 2012.

30 En la agenda digital europea, en el Safer programme, y en el Plan Estatal de Ciencia y Técnica e Innovación, que incluye como prioridad 7 del punto 6.4.7 "Ciberseguridad y confianza digital... (iii) protección a colectivos especialmente vulnerables”. La autorregulación suscrita en diciembre de 2011 por la Coalición CEO: http://ec.europa.eu/digitalagenda/en/self-regulation-better-internet-kids 